\title{
Brand Familiarity and Product Knowledge in Customization
}

\author{
Oksana Loginova*
}

May 21, 2009

\begin{abstract}
This paper challenges the assumption commonly used in the theoretical literature on customization that consumers always get their ideal varieties when they purchase a customized product. I adopt Hotelling's horizontal differentiation model with two firms competing for a continuum of consumers. Each consumer has a most preferred variety and possesses a certain level of category-specific knowledge. Initially, the firms produce standard products located at the end points of the variety interval. Suppose one of the firms offers customization. Consumers familiar with the brand can easily transfer their needs into appropriate characteristics of this brand. Consumers unfamiliar with the brand have difficulty in expressing their preferences. Category-specific knowledge is crucial here. Knowledgeable consumers are more capable of analyzing information than less knowledgeable ones, and the products they design better match their preferences. The game runs as follows. First, the firms simultaneously decide whether to offer customization, then engage in price competition. I show that while customization makes the products less differentiated, the frictions introduced into consumer co-design activities relax price competition. As a result, customization by one of the firms occurs in equilibrium.
\end{abstract}

Key words: horizontal differentiation, price competition, customization, brand familiarity, product knowledge

JEL codes: D43, L13, C72

*Department of Economics, University of Missouri-Columbia, 118 Professional Building, Columbia, MO 65211-6040, USA. E-mail: loginovao@missouri.edu, phone: +1-573-882-0063, fax: +1-573-882-2697. 


\section{Introduction}

Mass customization is the capability to produce individually tailored products without significantly compromising cost efficiency. ${ }^{1}$ Advances in Internet-based information technologies and manufacturing flexibility have made customization a reality in many product categories. For example, Dell builds to order notebook and desktop computers; NIKEiD and mi adidas allow consumers to create their most preferred athletic pair of shoes; apparel vendor Lands' End offers custom-crafted pants and shirts; Timissimo customizes wrist watches.

Considerable attention has been paid to customization in operations management and information systems studies. A number of papers have analyzed customization theoretically, drawing upon the existing literature in spatial and horizontal product differentiation. ${ }^{2}$ Customization enables firms to take advantage of consumers' desires for ideal varieties, but reduces differentiation and intensifies price competition. Indeed, if two or more firms offer a consumer the product that completely matches the consumer's tastes, then competition leads to marginal cost pricing (Syam, Ruan, and Hess, 2005, Bernhardt, Liu, and Serfes, 2007, Mendelson and Parlaktürk, 2008).

Customization differs from the strategy of offering as many variants as possible. With customization, the consumer interacts with the firm to create his/her product. In other words, the consumer must specify the characteristics of the product during design, fabrication, and assembly. While these co-design activities are the necessary prerequisites of customization in order to fulfil the needs of individual customers, they can also lead to frustration and information overload. Consumers often lack the knowledge and skills to transfer their needs into concrete product specification (Huffman and Kahn, 1998, Piller, Schubert, et al., 2005, Dellaert and Stremersch, 2005, Arora, Dreze et al., 2008). Even a simple product like a pair of NIKEiD shoes becomes a rather complex product if one has to decide explicitly between style, width and cushioning options for the insole, fabrics for the outsole, and colors options. Thus, critical to co-design are brand familiarity and category-specific knowledge of the consumer (Alba and Hutchinson, 1987, Jiang, 2004, Simonson, 2005, Ghosh, Dutta, and Stremersch, 2006).

In this paper I challenge the assumption commonly used in the theoretical literature that consumers possess sufficient knowledge to map their preferences into appropriate product characteristics. I adopt the standard Hotelling model with two firms competing for a continuum of consumers. Consumers are heterogenous in two dimensions. Each

\footnotetext{
${ }^{1}$ See Pine (1993) and Tseng and Jiao (2001) for examples and implementation of mass customization.

${ }^{2}$ The study of horizontal differentiation dates back to Hotelling (1929), and was extended by Lancaster (1966, 1979) and Salop (1979).
} 
consumer has a most preferred variety and possess a certain level of category-specific knowledge. Initially, the firms produce standard products located at the end points of the variety interval. Half of consumers buy from one firm, and the other half - from the other firm. Suppose one of the firms offers customization. Consumers familiar with the brand (as they have purchased from this firm in the past) can easily transfer their needs into appropriate characteristics of this brand. Consumers unfamiliar with the brand have difficulty in expressing their preferences. Category-specific knowledge is crucial here. Knowledgeable consumers are more capable of analyzing information than less knowledgeable ones, and the products they develop better match their preferences.

The timeline of the game is as follows. First, the firms simultaneously decide whether to offer customization. ${ }^{3}$ After customization decisions are made, the firms engage in price competition. Consumers decide which products to purchase, and the profits are realized. Since the goal of this paper is to investigate how the frictions introduced into co-design activities affect competition, I consider a benchmark setting in which consumers always get their ideal varieties when they purchase from a customizing firm. In the benchmark the firms have dominant strategies not to offer customization. In the model with frictions, the firms are able to avoid the disastrous price competition. I show that customization by one of the firms occurs in equilibrium.

The paper that is closest in spirit to the present study is Syam, Krishnamurthy, and Hess (2008). The authors construct an analytical model of consumers' uncertain preferences and anticipated regret in the context of customization. Prior to making a purchase, the consumer has a "fuzzy" ideal point. Only after the product has been purchased and used the consumer learns his true ideal point. The regret is captured by the loss in utility, if any, from buying the customized product compared to what the standard product would have provided. The authors' findings imply that there always exist a segment of consumers who prefer the standard product to the customized product, even though the customizing firm offers every possible product design at the same price.

The rest of the paper is organized as follows. In the next section I introduce the model. Section 3 is devoted to the benchmark setting. Equilibrium analysis is presented in Section 4. Concluding remarks are provided in Section 5. Proofs of all propositions are relegated to the Appendix.

\footnotetext{
${ }^{3}$ I do not allow the firms to offer customized products in addition to their standard products. The role of standard products in customization competition are studied in Dewan, Jing, and Seidmann (2003) and Syam and Kumar (2006).
} 


\section{The Model}

Two firms compete in a market with heterogenous consumers. Firm A produces brand $\mathrm{A}$ and firm B produces brand B. Each firm has a standard product located on the Hotelling line of length one, firm $\mathrm{A}$ at $x_{A}=0$ and firm $\mathrm{B}$ at $x_{B}=1$. Investing $k \geq 0$ into customization technology allows a firm to offer products that more closely match consumers' preferences. For simplicity, I assume that both standard and customized products are produced with zero marginal costs.

Consumers are heterogenous in two dimensions. Each consumer is identified by a point $(x, y)$ in a unit square $[0,1] \times[0,1]$, where $x$ is the consumer's most preferred variety and $y$ measures his product knowledge. Initially, consumers with $x<1 / 2$ are familiar with brand A and consumers with $x>1 / 2$ are familiar with brand B (as they have purchased from the two firms in the past). ${ }^{4}$

Consumer $(x, y)$ derives utility

$$
v-t x-p_{A}
$$

when he buys firm A's standard product at price $p_{A}$. Here, $v$ is a positive constant and $t$ measures the marginal disutility from consuming products away from $x$. Similarly, the consumer derives utility

$$
v-t(1-x)-p_{B}
$$

when he purchases firm B's standard product.

Next, suppose one of the firms, say firm A, offers customization. Consumers familiar with brand A are capable of transferring their needs into appropriate brand A's characteristics. Hence, they get their ideal varieties and derive utility

$$
v-p_{A} .
$$

In contrast, consumers unfamiliar with brand A experience difficulties in mapping their preferences into brand A's characteristics. Specifically, consumer $(x, y)$ derives utility

$$
v-y t x-p_{A} .
$$

The consumer's knowledge of the product category, $y$, is crucial in this situation. Lower values of $y$ correspond to more knowledge. The smaller is $y$, the better match the

\footnotetext{
${ }^{4} \mathrm{I}$ assume symmetry for tractability. This assumption does not undermine the main point of the paper.
} 
consumer gets when he purchases a customized product of an unfamiliar brand.

Each consumer has a unit demand. I will assume that $v$ is large enough for all consumers to find a product that yields positive payoff in equilibrium. Consumers are uniformly distributed over the unit square with a total mass equal to one.

The game has two stages. The first stage is the customization stage, in which the firms simultaneously decide whether to customize. These decisions become observable after they are made. In the second stage the firms simultaneously choose prices, consumers decide which products to purchase, and profits are realized. The equilibrium concept employed is subgame perfect Nash equilibrium.

\section{The Benchmark}

In this section I consider a benchmark setting in which consumers always get their ideal varieties when they purchase a customized product. Algebraically, all consumers have $y=0$, so consumer space becomes one-dimensional.

I will proceed using backward induction, starting with the pricing stage. There are four subgames to consider: both firms choose not to customize (NN), only firm A customizes (YN), only firm B customizes (NY), and both firms customize (YY).

Subgames NN and YY are straightforward. When no firm customizes, the equilibrium prices and profits are as in the standard Hotelling model. That is,

$$
p_{A}^{N N}=p_{B}^{N N}=t \quad \text { and } \quad \Pi_{A}^{N N}=\Pi_{B}^{N N}=\frac{t}{2} .
$$

Horizontal differentiation disappears when both firms customize, leading to the Bertrand outcome. Thus, in subgame YY we have

$$
p_{A}^{Y Y}=p_{B}^{Y Y}=0 \quad \text { and } \quad \Pi_{A}^{Y Y}=\Pi_{B}^{Y Y}=0
$$

Next, suppose firm A is the only customizing firm (subgame YN). The consumer located at $x$ purchases from firm $\mathrm{A}$ if and only if

$$
v-p_{A}>v-t(1-x)-p_{B} .
$$

Therefore, the marginal consumer type is

$$
\hat{x}=1-\frac{p_{A}-p_{B}}{t} .
$$


The firms' profit functions are

$$
\Pi_{A}\left(p_{A}, p_{B}\right)=\hat{x}\left(p_{A}, p_{B}\right) p_{A} \quad \text { and } \quad \Pi_{B}\left(p_{A}, p_{B}\right)=\left(1-\hat{x}\left(p_{A}, p_{B}\right)\right) p_{B}
$$

The first-order conditions yield

$$
p_{A}^{Y N}=\frac{2 t}{3} \quad \text { and } \quad p_{B}^{Y N}=\frac{t}{3}
$$

Under these prices firm A serves $2 / 3$ of the market and firm B serves $1 / 3$ of the market. The resulting profits are

$$
\Pi_{A}^{Y N}=\frac{4 t}{9} \quad \text { and } \quad \Pi_{B}^{Y N}=\frac{t}{9} .
$$

Compared to subgame NN, the decrease in horizontal differentiation intensifies price competition, leading to lower equilibrium prices.

Having analyzed the pricing stage, we move one step back to study the customization stage. The firms simultaneously choose between not customizing $(\mathrm{N})$ and customizing (Y). This stage is represented by the following matrix.

\section{Firm B}

\begin{tabular}{cc|c|c}
\multirow{2}{*}{ Firm A } & & $\mathrm{N}$ & $\mathrm{Y}$ \\
\cline { 2 - 4 } & $\mathrm{N}$ & $\frac{t}{2}, \frac{t}{2}$ & $\frac{t}{9}, \frac{4 t}{9}-k$ \\
\cline { 2 - 4 } & $\mathrm{Y}$ & $\frac{4 t}{9}-k, \frac{t}{9}$ & $-k,-k$
\end{tabular}

It follows that the unique equilibrium is $(\mathrm{N}, \mathrm{N})$ for any value of $k$. In other words, customization does not occur in the equilibrium of the benchmark setting.

\section{Equilibrium Analysis}

I will first derive equilibrium prices and profits given the firms' choices in the customization stage. Obviously, subgame NN leads to the equilibrium outcome of the standard Hotelling model.

Now suppose both firms customize (subgame YY). In contrast to the Bertrand outcome obtained in the benchmark, the two distinctive components of the model - brand familiarity and product knowledge - create differentiation between the firms' customized products, relaxing price competition. The firms set their prices above marginal costs, $p_{A}^{Y Y}=p_{B}^{Y Y}>0$. Because the firms' prices are equal in equilibrium, consumers with $x<1 / 2$ buy from firm A and the rest - from firm B. In other words, all consumers get their preferred varieties! Specifically, we have the following proposition. 


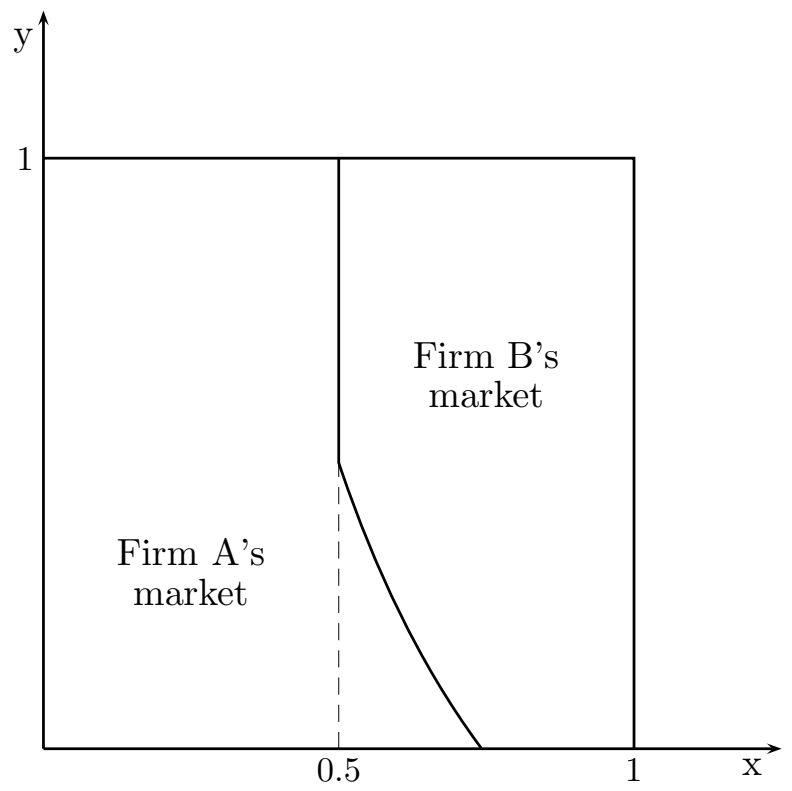

Figure 1: The firms' equilibrium market shares in subgame YN

Proposition 1 (Equilibrium prices in subgame YY). Suppose both firms customize. Then the equilibrium prices and profits are

$$
p_{A}^{Y Y}=p_{B}^{Y Y}=\frac{t}{2 \ln 2} \approx 0.72 t
$$

and

$$
\Pi_{A}^{Y Y}=\Pi_{B}^{Y Y}=\frac{t}{4 \ln 2} \approx 0.36 t .
$$

Consumers with $x<1 / 2$ purchase from firm $A$ and consumers with $x>1 / 2$ purchase from firm $B$.

Subgames NY and YN lead to symmetric results. Thus, it suffices to study one of them, subgame YN. As in the benchmark, firm A (the customizing firm) sets a higher price than firm B in equilibrium. In Proposition 2 I show that the difference between the equilibrium prices is less than $t / 2$, which implies that none of the consumers familiar with brand A will switch to brand B. However, some knowledgable consumers familiar with brand B will buy from firm A. This is illustrated in Figure 1.

Proposition 2 (Equilibrium prices in subgame YN). Suppose firm A customizes and 
firm $B$ does not. Then the equilibrium prices and profits are

$$
\left\{\begin{array} { l } 
{ p _ { A } ^ { Y N } \approx 1 . 3 9 t } \\
{ p _ { B } ^ { Y N } \approx 1 . 1 4 t }
\end{array} \text { and } \left\{\begin{array}{l}
\Pi_{A}^{Y N} \approx 0.77 t \\
\Pi_{B}^{Y N} \approx 0.51 t
\end{array}\right.\right.
$$

Consumers with $x<1 / 2$, as well as consumers with

$$
x \in\left(\frac{1}{2}, \frac{t-p_{A}^{Y N}+p_{B}^{Y N}}{t}\right) \quad \text { and } \quad y<\frac{t(1-x)-p_{A}^{Y N}+p_{B}^{Y N}}{t x}
$$

purchase from firm $A$, the rest purchase from firm $B$.

Note that the equilibrium prices (and profits) are higher than those in subgame YN of the benchmark. The intuition behind this result is, again, that brand familiarity and product knowledge reduce price competition between the firms.

Proceeding with backward induction, we analyze the firms' equilibrium customization choices in the first stage of the game. It is represented by the following matrix.

\begin{tabular}{cc|c|c} 
& & \multicolumn{2}{|c}{ Firm B } \\
Firm A & $\mathrm{N}$ & $\mathrm{Y}$ \\
\cline { 2 - 4 } & $\mathrm{N}$ & $0.5 t, 0.5 t$ & $0.51 t, 0.77 t-k$ \\
\cline { 2 - 4 } & $\mathrm{Y}$ & $0.77 t-k, 0.51 t$ & $0.36 t-k, 0.36 t-k$
\end{tabular}

Hence, we have the following proposition.

Proposition 3 (Equilibrium customization choices). If $k<0.27 t,(N, Y)$ and $(Y, N)$ are the two pure-strategy Nash equilibria; if $k>0.27 t,(N, N)$ is the unique equilibrium.

Recall that in the benchmark setting no firm customizes in equilibrium, even though all consumers get their most preferred varieties when they purchase from a customizing firm. In this model customization is not frictionless, yet, customization by one of the firms is an equilibrium outcome for sufficiently small values of $k$ !

\section{Concluding Remarks}

The existing theoretical studies explore how customizing firms escape the disastrous price competition. For example, Dewan, Jing, and Seidmann (2003) develop a model of product customization on a circle, in which two exogenously located firms choose customization scopes (arc segments). The firms do not compete head-to-head, as the scopes are disjoint. Syam, Ruan, and Hess (2005) endow products with two attributes 
and the firms in a duopoly decide which attributes to customize. In equilibrium each firm customizes one and the same attribute, thus minimizing price rivalry.

The present paper offered another explanation for why firms customize, focusing on consumers rather than on customization technology. The key assumption is that consumers do not always possess sufficient knowledge to specify the characteristics of the product that perfectly match their needs. While customization makes the products less differentiated, the frictions introduced into co-design activities work in the opposite direction to relax price competition. Customization by one of the firms occurs in equilibrium.

\section{References}

[1] Alba, Joseph W., and J. Wesley Hutchinson, 1987, "Dimensions of Consumer Expertise," Journal of Consumer Research, 13(4), pp. 411-454.

[2] Arora, Neeraj, Xavier Dreze, Anindya Ghose, James D. Hess, Raghuram Iyengar, Bing Jing, Yogesh Joshi, V. Kumar, Nicholas Lurie, Scott Neslin, S. Sajeesh, Meng Su, Niladri Syam, Jacquelyn Thomas, and Z. John Zhang, 2008, "Putting One-toone Marketing to Work: Personalization, Customization, and Choice," Marketing Letters, 19(3-4), pp. 305-321.

[3] Bernhardt, Dan, Qihong Liu, and Konstantinos Serfes, 2007, "Product Customization," European Economic Review, 51(6), pp. 1396-1422.

[4] Dellaert, Benedict G. C., and Stefan Stremersch, 2005, "Marketing MassCustomized Products: Striking a Balance Between Utility and Complexity," Journal of Marketing Research, 42(2), pp. 219-227.

[5] Dewan, Rajiv, Bing Jing, and Abraham Seidmann, 2003, "Product Customization and Price Competition on the Internet," Management Science, 49(8), pp. 1055-1070.

[6] Ghosh, Mrinal, Shantanu Dutta, and Stefan Stremersch, 2006, "Customizing Complex Products: When Should the Vendor Take Control?" Journal of Marketing Research, 43(4), pp. 664-679.

[7] Hotelling, Harold, 1929, "Stability in Competition," Economic Journal, 39(153), pp. 41-57.

[8] Huffman, Cynthia, and Barbara E. Kahn, 1998, "Variety for Sale: Mass Customization or Mass Confusion?" Journal of Retailing, 74(4), pp. 491-513. 
[9] Jiang, Pingjun, 2004, "The Role of Barnd Name in Customization Decisions: A Search vs Experience Perspective," Journal of Product and Brand Management, 13(2), pp. 73-83.

[10] Lancaster, Kelvin J., 1966, "A New Approach to Consumer Theory," Journal of Political Economy, 74(2), 132-157.

[11] Lancaster, Kelvin J., 1979, Variety, Equity and Efficiency, Columbia University Press, New York.

[12] Mendelson, Haim, and Ali K. Parlaktürk, 2008, "Competitive Customization," Manufacturing and Service Operations Management, 10(3), pp. 377-390.

[13] Pine, B. Joseph, 1993, Mass Customization: The New Frontier in Business Competition, Harvard Business School Press, Boston, MA.

[14] Salop, Steven C., 1979, "Monopolistic Competition with Outside Goods," Bell Journal of Economics, 10(1), pp. 141-156.

[15] Simonson, Itamar, 2005, "Determinants of Customers' Responses to Customized Offers: Conceptual Framework and Research Propositions," Journal of Marketing, 69(1), pp. 32-45.

[16] Syam, Niladri B., Partha Krishnamurthy, and James D. Hess, 2008, "That's What I Thought I Wanted? Miswanting and Regret for a Standard Good in a MassCustomized World," Marketing Science, 27(3), pp. 379-397.

[17] Syam, Niladri B., and Nanda Kumar, 2006, "On Customized Goods, Standard Goods, and Competition," Marketing Science, 25(5), pp. 525-537.

[18] Syam, Niladri B., Ranran Ruan, and James D. Hess, 2005, "Customized Products: A Competitive Analysis," Marketing Science, 24(4), pp. 569-584.

[19] Tseng, Mitchel M., Jianxin Jiao, 2001, "Mass Customization," in Handbook of Industrial Engineering, Wiley, New York.

[20] Piller, Frank, Petra Schubert, Michael Koch, and Kathrin Moslein, 2005, "Overcoming Mass Confusion: Collaborative Customer Co-design in Online Communities," Journal of Computer-Mediated Communication, 10(4), article 8. 


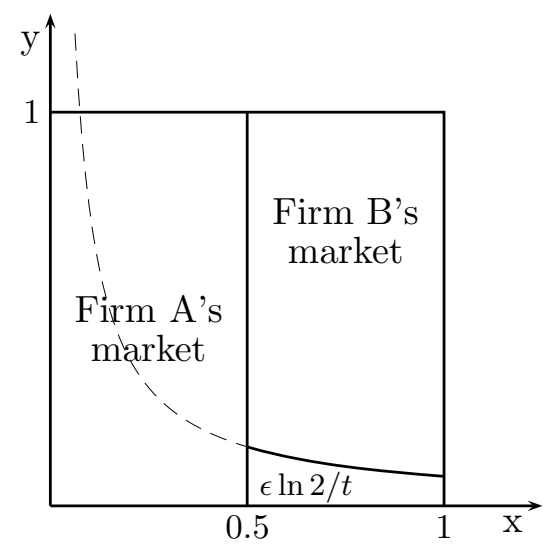

Figure 2: Deviation by firm A in subgame YY

\section{Appendix}

Proof of Proposition 1. Let $p_{A}^{Y Y}=p_{B}^{Y Y}=p$ and consider a unilateral deviation by firm A. If firm A decreases its price by $\epsilon$, then some consumers will switch from firm B to firm A. These are consumers with small $y$ 's:

$$
v-y t x-p_{A}<v-p_{B}
$$

or

$$
y<\frac{p_{B}-p_{A}}{t x}=\frac{\epsilon}{t x} .
$$

Thus, firm A's market increases (firm B's market decreases) by

$$
\int_{\frac{1}{2}}^{1} \frac{\epsilon}{t x} \mathrm{~d} x=\frac{\epsilon \ln 2}{t}
$$

as illustrated in Figure 2. Firm A's new profit is

$$
\left(\frac{1}{2}+\frac{\epsilon \ln 2}{t}\right)(p-\epsilon)=\frac{p}{2}+\epsilon\left(\frac{p \ln 2}{t}-\frac{1}{2}\right)-\frac{\epsilon^{2} \ln 2}{t} .
$$

Equilibrium requires that firm $\mathrm{A}$ has no incentives to deviate, hence it must be that case that

$$
\frac{p \ln 2}{t}-\frac{1}{2}=0,
$$

or

$$
p=\frac{t}{2 \ln 2} .
$$


Proof of Proposition 2. Consider $p_{A}$ and $p_{B}$ such that

$$
p_{B}<p_{A}<p_{B}+\frac{t}{2}
$$

In this case none of the consumers familiar with brand A will buy firm B's standard product. However, some of the consumers familiar with brand B will buy firm A's customized product:

$$
v-y t x-p_{A}<v-t(1-x)-p_{B}
$$

or

$$
y<\frac{t(1-x)-p_{A}+p_{B}}{t x},
$$

as illustrated in Figure 1. Let $S\left(p_{A}, p_{B}\right)$ denote the number of these consumers,

$$
\begin{aligned}
S\left(p_{A}, p_{B}\right) & =\int_{\frac{1}{2}}^{1-\frac{p_{A}-p_{B}}{t}} \frac{t(1-x)-p_{A}+p_{B}}{t x} \mathrm{~d} x \\
& =\frac{1}{2}-\left(1-\frac{p_{A}-p_{B}}{t}\right)\left(1-\ln \left(2\left(1-\frac{p_{A}-p_{B}}{t}\right)\right)\right) .
\end{aligned}
$$

The firms' profit functions are, therefore,

$$
\Pi_{A}\left(p_{A}, p_{B}\right)=\left(\frac{1}{2}+S\left(p_{A}, p_{B}\right)\right) p_{A}
$$

and

$$
\Pi_{B}\left(p_{A}, p_{B}\right)=\left(\frac{1}{2}-S\left(p_{A}, p_{B}\right)\right) p_{B} .
$$

Taking the first-order conditions leads to the system of equations

$$
\left\{\begin{array}{l}
\frac{\partial S}{\partial p_{A}} p_{A}+\frac{1}{2}+S=0 \\
-\frac{\partial S}{\partial p_{B}} p_{B}+\frac{1}{2}-S=0
\end{array}\right.
$$

where

$$
\frac{\partial S}{\partial p_{A}}=-\frac{\partial S}{\partial p_{B}}=-\frac{1}{t} \ln \left(2\left(1-\frac{p_{A}-p_{B}}{t}\right)\right)
$$

Let

$$
z \equiv 1-\frac{p_{A}-p_{B}}{t}
$$


Note that (1) implies $z \in(1 / 2,1)$. Then

$$
S=\frac{1}{2}-z(1-\ln (2 z))
$$

and

$$
\frac{\partial S}{\partial p_{A}}=-\frac{\partial S}{\partial p_{B}}=-\frac{\ln (2 z)}{t} .
$$

The first-order conditions can be rewritten as

$$
\left\{\begin{array}{l}
-\frac{\ln (2 z)}{t} p_{A}+1-z(1-\ln (2 z))=0 \\
-\frac{\ln (2 z)}{t} p_{B}+z(1-\ln (2 z))=0 .
\end{array}\right.
$$

Subtracting the first equation from the second and substituting

$$
\frac{p_{A}-p_{B}}{t}=1-z
$$

yields

$$
\ln (2 z)(1-z)-1+2 z(1-\ln (2 z))=0 .
$$

There is only one solution to $(3)$ on $(1 / 2,1)$, approximately equal to $z^{*} \approx 0.74$. The equilibrium prices can be found from (2),

$$
p_{A}^{Y N}=\frac{1-z^{*}\left(1-\ln \left(2 z^{*}\right)\right)}{\ln \left(2 z^{*}\right)} t \approx 1.39 t
$$

and

$$
p_{B}^{Y N}=\frac{z-z^{*} \ln \left(2 z^{*}\right)}{\ln \left(2 z^{*}\right)} t \approx 1.14 t .
$$

Observe that the equilibrium prices satisfy (1). The equilibrium value of $S$ is

$$
S^{*}=\frac{1}{2}-z^{*}\left(1-\ln \left(2 z^{*}\right)\right) \approx 0.05 t .
$$

Hence, the equilibrium profits are

$$
\Pi_{A}^{Y N}=\left(\frac{1}{2}+S^{*}\right) p_{A}^{Y N} \approx 0.77 t
$$

and

$$
\Pi_{B}^{Y N}\left(\frac{1}{2}-S^{*}\right) p_{B}^{Y N} \approx 0.51 t
$$

